\title{
In situ growth optimization in focused electron-beam induced deposition
}

\author{
Paul M. Weirich, Marcel Winhold, Christian H. Schwalb ${ }^{*}$ and Michael Huth
}

\section{Full Research Paper}

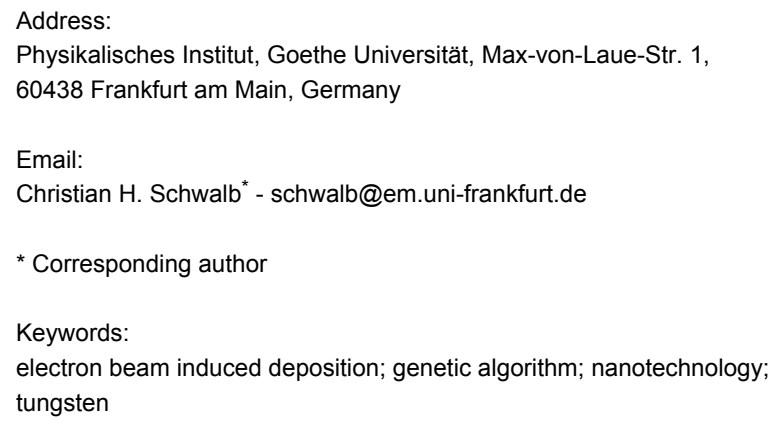

Beilstein J. Nanotechnol. 2013, 4, 919-926. doi:10.3762/bjnano.4.103

Received: 07 August 2013

Accepted: 06 December 2013

Published: 17 December 2013

Associate Editor: A. Gölzhäuser

(C) 2013 Weirich et al; licensee Beilstein-Institut.

License and terms: see end of document.

\begin{abstract}
We present the application of an evolutionary genetic algorithm for the in situ optimization of nanostructures that are prepared by focused electron-beam-induced deposition (FEBID). It allows us to tune the properties of the deposits towards the highest conductivity by using the time gradient of the measured in situ rate of change of conductance as the fitness parameter for the algorithm. The effectiveness of the procedure is presented for the precursor $\mathrm{W}(\mathrm{CO})_{6}$ as well as for post-treatment of Pt-C deposits, which were obtained by the dissociation of $\mathrm{MeCpPt}(\mathrm{Me})_{3}$. For $\mathrm{W}(\mathrm{CO})_{6}$-based structures an increase of conductivity by one order of magnitude can be achieved, whereas the effect for $\mathrm{MeCpPt}(\mathrm{Me})_{3}$ is largely suppressed. The presented technique can be applied to all beam-induced deposition processes and has great potential for a further optimization or tuning of parameters for nanostructures that are prepared by FEBID or related techniques.
\end{abstract}

\section{Introduction}

In focused electron-beam-induced deposition, FEBID in short, a (metal-)organic or inorganic volatile precursor gas, which was previously adsorbed on a substrate surface, is dissociated in the focus of an electron beam provided by a scanning (SEM) or transmission electron microscope (TEM). During the last decade FEBID has developed from a highly specialized nanofabrication method with a limited selection of application fields to one of the most flexible approaches for functional nanostructure fabrication with true $3 \mathrm{D}$ patterning capabilities. By now FEBID-based nanostructures are used in highly minia- turized magnetic field $[1,2]$, strain/force $[3,4]$ and gas sensing [5] applications, as well as in micromagnetic studies on domain wall nucleation and propagation [6,7]. On the basis of the in situ, electron irradiation-induced tunability of metallic FEBID-structures significant progress could be made in understanding the charge transport regimes in nanogranular metals [8-10]. In addition, by the controlled combination of two precursors it has become possible to prepare amorphous binary alloys $[11,12]$, as well as nanogranular intermetallic compounds [13]. 
As the FEBID-immanent parameter space becomes larger, the identification of the parameters for an optimal deposition protocol is becoming a very challenging problem. In fact, even for a single organometallic precursor, finding the deposition parameters for, e.g., obtaining the maximum possible metal content, can be a difficult task. This can be exemplified for the commonly used precursor $\mathrm{W}(\mathrm{CO})_{6}$. Rosenberg and co-workers recently studied the electron-dose and substrate-temperature dependence on the final deposit in electron-induced dissociation experiments with $500 \mathrm{eV}$ electron energy for this precursor $[14,15]$. They showed that the initial dissociation at electron doses below about $100 \mathrm{pC} / \mu^{2}$ leads to the release (i.e., dissociation and desorption) of two CO ligands from the parent molecule. The decarbonylated residual species is then subject to an electron-stimulated decomposition rather than to a desorption, which results in an average composition of the deposit of $[\mathrm{W}] /[\mathrm{C}] \approx 1 / 4$. By increasing the electron dose and/or the substrate temperature, which causes changes in the coverage and average residence time of the precursor molecules on the surface, the metal content can be increased to above 40 atom $\%$ [16]. Changes of the precursor flux and the partial pressure of water in the residual gas also influence the final composition and increases the extend of tungsten oxidation in the deposit [15].

With regard to the electrical conductivity of the deposits, a key quantity in many applications of FEBID structures, no reliable prediction can be made concerning its value for different deposition parameters and conditions. This is due to the fact that the metal content alone is not a sufficient indicator since in most instances transport is of the hopping type, so that the matrix composition and the oxidation state of the metal are also important but a-priori unknown quantities $[4,8]$. From this, one can conclude that the optimization of any FEBID process towards the largest possible conductivity should ideally monitor the conductance as the growth proceeds [10] and use this information in adaptively changing the deposition parameters. Here, we present a first implementation of such a feedback control mechanism and employ an evolutionary genetic algorithm (GA) for the in situ optimization of the electrical conductivity of nanostructures that are prepared by FEBID [17]. By using the time gradient of the measured in situ conductance as a fitness parameter for the GA we are able to tune the properties of the deposits towards highest conductivity. In order to demonstrate the efficiency of this method, we chose $\mathrm{W}(\mathrm{CO})_{6}$. Our study reveals that an increase of conductivity by one order of magnitude can be achieved with the GA by solely varying the process parameters pitch $p$ and dwell-time $t_{\mathrm{D}}$ in the deposition process. The precursor-specific limitations of the approach are also exemplified for another precursor, $\operatorname{MeCpPt}(\mathrm{Me})_{3}$, which is known to show only one bond-cleavage in the initial step [18].
This results in a $\mathrm{Pt} / \mathrm{C}$ ratio that is largely independent from the deposition parameter. Furthermore, in contrast to tungsten, platinum is not susceptible to oxidation or carbide formation, which results in a nano-granular rather than amorphous microstructure.

\section{Experimental}

The FEBID process takes place in a dual-beam SEM/FIB microscope (FEI, Nova Nanolab 600) equipped with a Schottky electron emitter. The precursor gases are introduced into the high-vacuum chamber via a gas injection system through a thin capillary (diameter $=0.5 \mathrm{~mm}$ ) in close proximity to the focus of the electron beam. As a substrate material n-doped $\operatorname{Si}(100)$ $(350 \mu \mathrm{m}) / \mathrm{LPCVD} \mathrm{Si}_{3} \mathrm{~N}_{4}(300 \mathrm{~nm})$ was used, which was equipped with $10 / 200 \mathrm{~nm}$ thick $\mathrm{Cr} / \mathrm{Au}$ contacts with a separation of $3 \mu \mathrm{m}$ that were prepared by using UV-lithography and a lift-off process. The optimization process by using the GA in combination with in situ electrical conductance measurements is schematically displayed in Figure 1a. At first a seedlayer is deposited in order to ensure that all optimization processes start with the same initial conditions. On top of the seed layer subsequent layers with different deposition parameters are added.

With regard to a GA-based optimization process, the set of parameters used for the deposition of one specific layer consists of the $\mathrm{x}$ - and $\mathrm{y}$-size of the deposit, the dwell time $\left(t_{\mathrm{D}}\right)$, the pitch in $\mathrm{x}\left(p_{\mathrm{x}}\right)$ and $\mathrm{y}\left(p_{\mathrm{y}}\right)$ direction, the beam current $(I)$, the acceleration voltage $(U)$, the temperature $(T)$, refresh-time $\left(t_{r}\right)$, scantype (raster or serpentine), dose $(D)$ and passes $(P)$. However, not all parameters are independent, e.g., in order to keep $D$ fixed, $P$ has to be adapted according to the specific combination of $\left\{\mathrm{x}-\right.$ and $\mathrm{y}$-size of the deposit, $p_{\mathrm{x}}$ and $p_{\mathrm{y}}, I$ and $\left.t_{\mathrm{D}}\right\}$. The aim of the search of the GA is to find parameter sets that will lead to an enhancement of conductance because of an increasing growth rate of the deposit and/or intrinsic effects, e.g., the increase of the metal content and/or a change of the dielectric matrix. The GA allows for the optimization of the deposition parameters for an arbitrary precursor, without having any additional information about the deposition process. Therefore, the following procedure is performed:

The parent optimization cycle based on the first $2 n$ parameter sets with randomly generated parameters is deposited onto the seed layer. After the deposition of each layer a fitness evaluation is carried out for each parameter set according to the following principle. During the optimization process the conductance $S$ is measured and the rate of change of conductance over time $\bar{S}^{\prime}=S / t$ is calculated. If an additional layer that is deposited on top of the existing structure is considered an added resistance, which is connected in parallel, $\overline{S^{\prime}}$ remains constant if the growth rate and the conductivity do not change. 


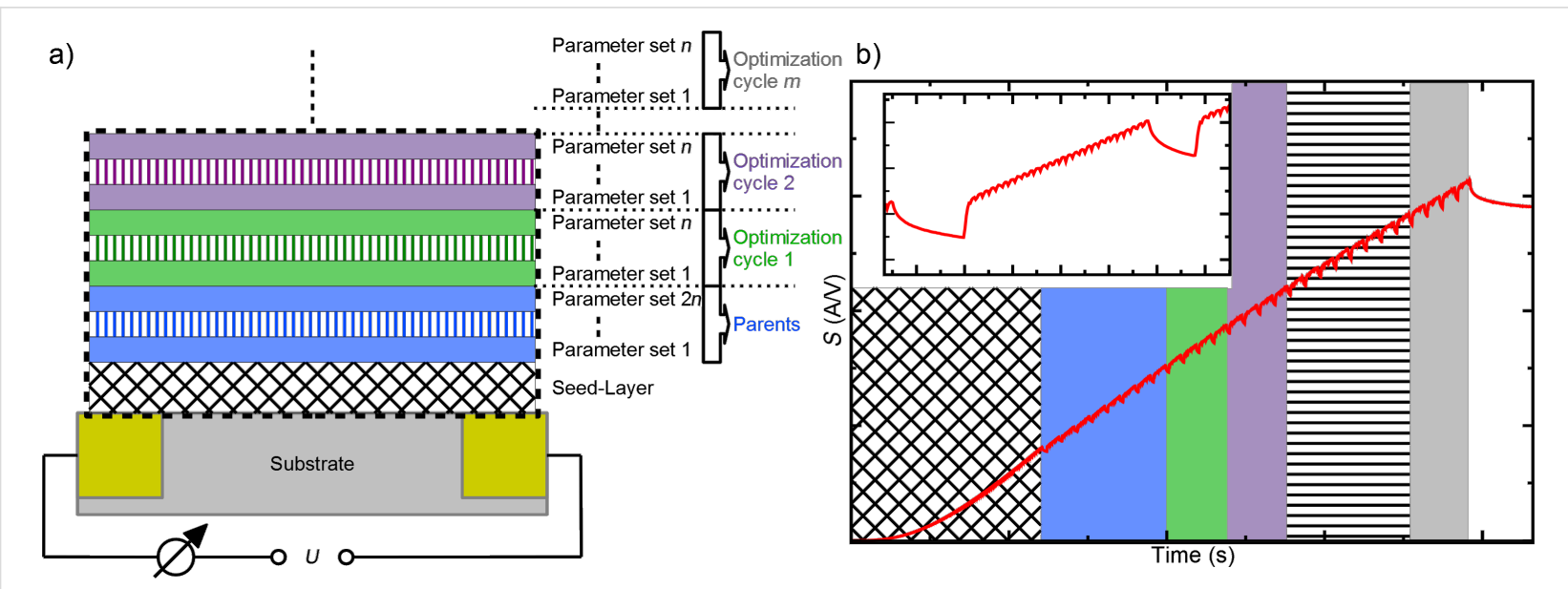

Figure 1: Schematic representation of the optimization process: (a) Layer structure of FEBID deposits: $m$ optimization cycles, each consisting of $n$ parameter sets except for the parent optimization cycle with $2 n$ parameter sets, are deposited onto a seed-layer between two $\mathrm{Cr} / \mathrm{Au}$ electrodes. During the deposition process the conductance of the whole layer structure is measured. (b) Representative $S(t)$-graph for the layer structure of (a). Altering background colors indicate the deposition of different optimization cycles. The inset depicts $S(t)$ during the deposition of one layer. The $S(t)$ curve shows a sharp increase when the FEBID process is started and decreases when the deposition process is stopped, respectively.

However, if either the conductivity or the growth rate are altered by the variation of deposition parameters, the gradient of $\bar{S}^{\prime}$ is a suitable variable to describe the influence of the deposition parameters on the conductance of the deposit. Hence, the gradient of $\overline{S^{\prime}}$ is chosen as the fitness parameter for the GA in order to detect effects that lead to a change of the growth rate and/or the conductivity. Layers with the highest fitness values are selected to generate the next optimization cycle of $n$ parameter sets by using genetic operators such as crossover and mutation. For the next optimization cycle a number of new parameter sets are created, according to half the size of the initial parent optimization cycle. One half of the next optimization cycle is created with the crossover method, the other half with the mutation method. The parents of the new parameter sets are chosen via an uniform distributed random choice. The crossover method is performed by exchanging parameters of the parents. For the mutation method parameters are chosen randomly within the given parameter-range. A representative time-dependent development of the conductance during the optimization process is shown in Figure 1b. The GA is stopped after a predefined number of $m$ optimization cycles yielding a set of FEBID parameters for each precursor for a deposit of optimized conductance. A flow-chart of the GA optimization process is shown in Figure 2.

\section{Results}

In order to check for the proper operation of the GA we first applied it for the optimization of deposition parameters for the widely used precursor $\mathrm{W}(\mathrm{CO})_{6}[10,19-21]$. For $\mathrm{W}(\mathrm{CO})_{6}$ it is well known that the metal content and, respectively, the conductivity strongly depend on the deposition parameters during the FEBID process. At the beginning a reference sample was deposited while using standard deposition parameters $\left(U=5 \mathrm{kV}, I=6.3 \mathrm{nA}, t_{\mathrm{D}}=100 \mu \mathrm{s}, p_{\mathrm{x}}=40 \mathrm{~nm}, p_{\mathrm{y}}=40 \mathrm{~nm}\right)$. For the reference sample the GA protocol was used, which means that the process was paused after the deposition of each

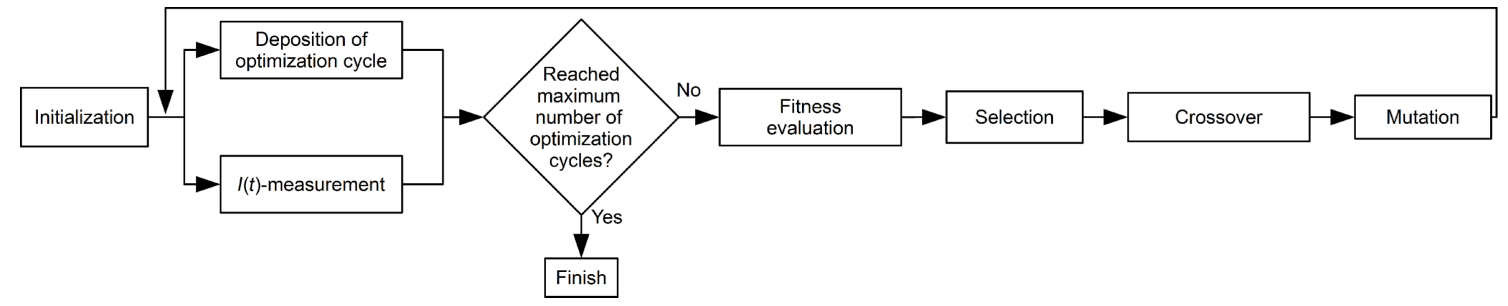

Figure 2: Flow chart of the in situ optimization of conductance of FEBID deposits with a GA. After the initialization of the program, the GA optimizes the conductance of the deposits by using the measured gradient of $\bar{S}^{\prime}$ to evaluate the fitness of the parameter sets used for deposition. Selection, recombination and mutation of parameter sets are carried out after the fitness evaluation to obtain the next optimization cycle with optimized parameter sets. The process is stopped after the deposition of a pre-defined number of optimization cycles. 
layer, indicated by the drops in the curves of Figure $3 \mathrm{a}$. However, for the reference sample the parameters were kept fixed for the complete deposition process. For each parameter set a dose of $3 \mathrm{nC} / \mu \mathrm{m}^{2}$ was used. The GA was carried out for 6 optimization cycles with a population size of 8 parameter sets. The measured rate of change of conductance during the FEBID process for the reference sample is displayed in Figure 3a (Sample 1). Subsequently the GA was applied for finding the optimized parameters for the deposition that used $\mathrm{W}(\mathrm{CO})_{6}$ as a precursor. First, only the dwell time $t_{\mathrm{D}}$ was used as optimization parameter and was allowed to vary in the range of $0.2-1500 \mu \mathrm{s}$. The corresponding rate of change of conductance is displayed in Figure 3a (Sample 2). In addition, we let the GA search for deposition parameters that lead to a minimum conductance. Dwell time $t_{\mathrm{D}}$ and pitch $p_{\mathrm{x}}, p_{\mathrm{y}}$ were allowed to vary in the range of $0.2-1500 \mu$ s and $30-200 \mathrm{~nm}$, respectively (Figure 3a, Sample 3). The highest conductance for $\mathrm{W}-\mathrm{C}-\mathrm{O}$ deposits was obtained for short dwell times $\left(t_{\mathrm{D}}=0.5 \mu \mathrm{s}\right)$ whereas a low conductance was observed for long dwell times $\left(t_{\mathrm{D}}=831 \mu \mathrm{s}\right)$ and a larger y-pitch $\left(p_{\mathrm{y}}=150 \mathrm{~nm}\right)$. In order to study the success of the GA procedure the optimized parameter sets returned by the GA for the highest and the lowest conductance as well as for the reference sample were used for a standard FEBID process and the conductance during the deposition was measured (see Figure 3b). As can be clearly seen, sample 2 (optimized for highest conductance) shows by far the highest value of conductance, whereas for sample 3 (optimized for lowest conductance) the lowest value is achieved.

For the purpose of characterizing the chemical composition of the different samples energy dispersive X-ray spectroscopy (EDX) was performed. EDX measurements were carried out on
$2 \times 2 \mu \mathrm{m}^{2}$ reference structures, which were deposited with the identical parameters that were used for the conductance measurements. In Figure 4a the results of the EDX measurements are displayed. Sample 2 has the highest metal content of 39.2 atom $\% \mathrm{~W}$, whereas the metal content decreases for reference sample 1 (32.7 atom \% W) and sample 3 (26.0 atom \% W). Apparently a difference of more than 13 atom $\%$ between the intentionally optimal and the worst parameter set can be observed. In addition the carbon content in the deposits increases from sample 2 to sample 3, whereas the oxygen content is reduced. The corresponding resistivity of the different samples was calculated from the conductance measurements in Figure $3 \mathrm{~b}$ in combination with AFM measurements of the deposits. As already indicated by the result of the EDX measurements the resistivity of the tungsten deposits is reduced by one order of magnitude for the optimized GA parameters compared to the GA parameters for lowest conductance. The results for the GA optimization for the $\mathrm{W}(\mathrm{CO})_{6}$ deposits are summarized in Table 1.

\section{Discussion}

For the thus far presented case of $\mathrm{W}(\mathrm{CO})_{6}$, the great success of the GA-optimization process is due to the fact that the metal content of the deposits can be tuned over a wide range and that it strongly depends on the deposition parameters, which is known to be the case for many carbonyl-based precursors (e.g., $\mathrm{W}(\mathrm{CO})_{6}[10,19,21], \mathrm{Co}_{2}(\mathrm{CO})_{8}[2,22]$ and $\left.\mathrm{Fe}(\mathrm{CO})_{5}[23,24]\right)$. With regard to the two process parameters dwell-time and pitch, the FEBID process can in general be divided into two deposition regimes. For small dwell-times and larger pitches the electron-induced dissociation reactions are locally limited by the number of incident electrons (reaction rate limited regime
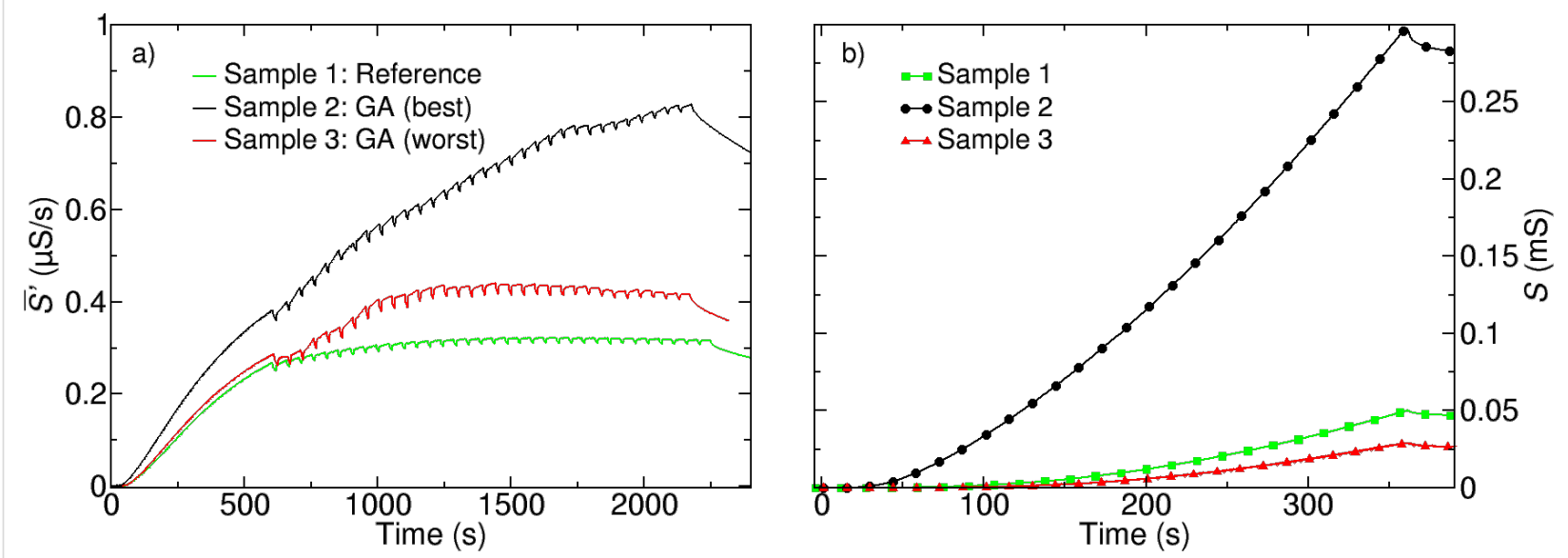

Figure 3: (a) Rate of change of conductance during the GA optimization for the W-C-O reference (green), GA-optimized deposit for highest conductance (black) and GA-optimized deposit for lowest conductance (red). For each parameter set a dose of $3 \mathrm{nC} / \mu \mathrm{m}^{2} \mathrm{was}$ used. The population size amounted to 8 parameter sets and 6 optimization cycles, which were deposited for the GA optimization. (b) Conductance of $A=3 \times 7 \mu m^{2} \mathrm{~W}-\mathrm{C}-\mathrm{O}$ structures deposited with parameters derived from the optimization processes in (a) as well as for the $\mathrm{W}-\mathrm{C}-\mathrm{O}$ reference when using a dose of $27 \mathrm{nC} / \mu \mathrm{m}^{2}$. 

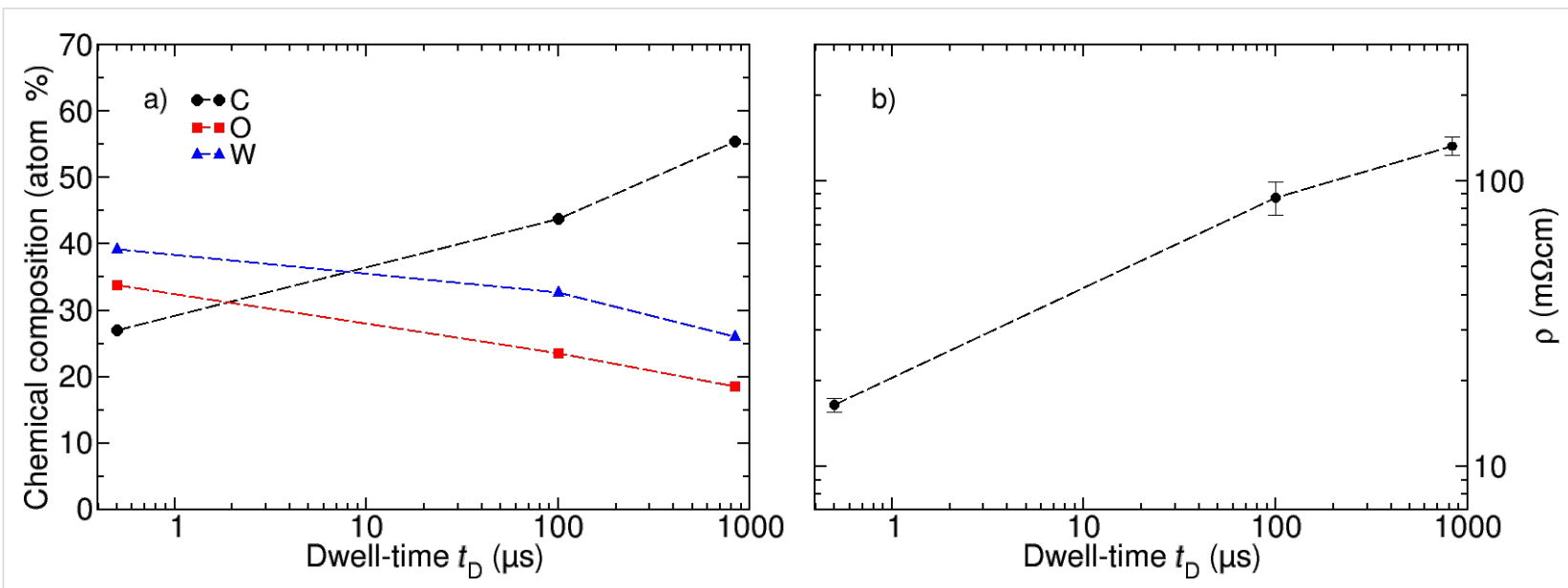

Figure 4: (a) Chemical composition of sample $1\left(t_{D}=100 \mu \mathrm{s}\right)$, sample $2\left(t_{D}=0.5 \mu \mathrm{s}\right)$ and sample $3\left(t_{D}=831 \mu \mathrm{s}\right)$. EDX measurements were performed on separate $2 \times 2 \mu \mathrm{m}^{2}$ samples. (b) Resistivity of samples 1, 2 and 3: By solely varying the deposition parameters dwell-time and pitch as obtained from the GA experiments, the resistivity of $\mathrm{W}-\mathrm{C}-\mathrm{O}$ samples can be tuned by one order of magnitude.

Table 1: Summary of parameters used for deposition of samples 1 (reference), 2 (GA-optimization for highest conductance) and 3 (GA-optimization for lowest conductance). The reference sample was deposited with fixed values for dwell-time and pitch whereas the dwell-time for sample 2 was varied by the GA in the range of $t_{\mathrm{D}}=0.2-1500 \mu \mathrm{s}$ at fixed pitch of $p_{\mathrm{x}}=p_{\mathrm{y}}=40 \mathrm{~nm}$. For sample 3 , dwell-time and pitch were both allowed to vary in the range of $t_{\mathrm{D}}=0.2-1500 \mu \mathrm{s}$ and $p_{\mathrm{x}}, p_{\mathrm{y}}=30-200 \mathrm{~nm}$. The GA-optimization was performed for 6 optimization cycles, each comprising 8 parameter sets, which were deposited between $\mathrm{Cr} / \mathrm{Au}$ electrodes by using a dose of $3 \mathrm{nC} / \mu^{2} \mathrm{~m}^{2}$ per parameter set. The parameters obtained from the in situ experimental GA analysis were used to deposit another set of samples with a dose of $27 \mathrm{nC} / \mu \mathrm{m}^{2}$ and $A=3 \times 7 \mu \mathrm{m}^{2}$, which were analyzed by means of AFM and electrical $I(V)$-measurements to obtain the resistivity of the samples. The chemical composition was determined by EDX-measurements that were performed on separate $2 \times 2 \mu \mathrm{m}^{2}$ samples in order to prevent changing the conductivity of the samples with respect to further electrical measurements. All other deposition parameters were kept fixed: $U=5 \mathrm{kV}, I_{\text {nominal }}=6.3 \mathrm{nA}$.

\begin{tabular}{|c|c|c|c|c|c|c|c|c|c|c|c|}
\hline $\begin{array}{c}\text { sample } \\
\text { no. }\end{array}$ & \multicolumn{3}{|c|}{ parameters varied by GA } & \multicolumn{3}{|c|}{$\begin{array}{l}\text { parameters used for } \\
\text { deposition }\end{array}$} & \multicolumn{3}{|c|}{ chemical composition } & \multirow{2}{*}{$\begin{array}{c}\text { resistivity } \\
\begin{array}{c}\rho \\
(\mathrm{m} \Omega \cdot \mathrm{cm})\end{array}\end{array}$} & \multirow{2}{*}{$\begin{array}{c}\text { height } \\
\begin{array}{c}\mathrm{h} \\
(\mathrm{nm})\end{array}\end{array}$} \\
\hline$\#$ & $\begin{array}{c}t_{D} \\
(\mu s)\end{array}$ & $\underset{(\mathrm{nm})}{p_{\mathrm{x}}}$ & $\begin{array}{c}p_{y} \\
(\mathrm{~nm})\end{array}$ & $\begin{array}{c}t_{\mathrm{D}} \\
(\mu \mathrm{s})\end{array}$ & $\begin{array}{c}p_{x} \\
(\mathrm{~nm})\end{array}$ & $\begin{array}{c}p_{y} \\
(\mathrm{~nm})\end{array}$ & $\begin{array}{c}\mathrm{W} \\
\text { (atom \%) }\end{array}$ & $\underset{(\text { atom \%) }}{\mathrm{C}}$ & $\begin{array}{c}\mathrm{O} \\
\text { (atom \%) }\end{array}$ & & \\
\hline 1 & - & - & - & 100 & 40 & 40 & 32.7 & 43.8 & 23.5 & 87.7 & 32 \\
\hline 2 & $0.2-1500$ & - & - & 0.5 & 40 & 40 & 39.2 & 27.0 & 33.8 & 16.5 & 36 \\
\hline 3 & $0.2-1500$ & $30-200$ & $30-200$ & 831 & 35 & 150 & 26.0 & 55.4 & 18.6 & 133.3 & 25 \\
\hline
\end{tabular}

$(\mathrm{RRL}))$. However, if the dwell-time is large and a small pitch is used, the reactions are limited by the number of available precursor molecules (mass transport limited regime (MTL)). In most cases the complete electron-induced dissociation of a precursor molecule is not a single-step process but requires several electron-precursor interactions $[25,26]$. Therefore in the $\mathrm{RRL}$ regime precursor molecules are not dissociated completely, which leads either to an implantation of non-dissociated precursor molecules or reaction byproducts into the deposit but also allowing reaction byproducts such as, e.g., $\mathrm{CO}$ groups to diffuse away from the electron impact area, to desorb and to finally be removed from the vacuum chamber. In the MTL regime due to the large number of locally available electrons, precursor molecules are rapidly depleted leaving enough electrons to dissociate reaction byproducts, which can be incorporated as non-metallic impurities into the deposit. With regard to our GA experiments RRL-like conditions [27] were fulfilled for sample 2, which was optimized by the GA for a maximum conductance. As it is evident from the ratio of $\mathrm{W} / \mathrm{C} / \mathrm{O}=$ 1:0.69:0.86, which was obtained by the EDX measurements, for a short dwell-time of $0.5 \mu$ s the electron-stimulated decomposition of the $\mathrm{W}$-precursor and its surrounding CO ligands is very efficient as only $14.3 \%$ and $11.5 \%$ of oxygen and carbon atoms, respectively, of the original $\mathrm{W}(\mathrm{CO})_{6}$ molecules are incorporated into the deposit. These findings suggest that due to the limited number of electrons available in the RRL regime the majority of volatile $\mathrm{CO}$ byproducts can be removed during the FEBID process, which leads to a deposit with a high metal content. On the contrary, for a dwell-time of $831 \mu$ s the growth regime shifts to MTL regime where the replenishment rate of precursor molecules is too low, which leads to further electron stimulated dissociation of $\mathrm{CO}$. The result is a strongly enhanced carbon content of 55.4 atom \% in the deposit that is accompanied by a decrease of tungsten and oxygen to 26.0 atom \% and 
18.6 atom \%, respectively. Furthermore, the oxygen content of the deposits is coupled to the amount of tungsten, which indicates that tungsten oxide is formed (Figure $4 b$ ). The strong increase of carbon in the deposits with decreasing oxygen content can be explained by the electron-induced decomposition of CO groups, which is in accordance with several studies on electron-induced dissociation of adsorbed and gaseous $\mathrm{CO}$ molecules [28,29]. Furthermore the studies show that carbon remains at the surface whereas oxygen is liberated, which is in agreement with our measurements. In order to describe the observed increase of conductance it is not sufficient to only regard the metal content as the growth rate can also have a significant impact. However, as depicted in Table 1, AFM measurements reveal that the height of samples $1-3$ varies by a factor of 1.44, which corresponds to a monotonic increase of height with decreasing dwell time from $25 \mathrm{~nm}$ to $36 \mathrm{~nm}$ for samples 3 and 2, respectively. Thus, for the presented case of $\mathrm{W}(\mathrm{CO})_{6}$ the growth rate only has a minor impact on conductance of the different samples.

The results of the GA optimization presented in this work for a precursor that is sensitive to the deposition parameters are extremely promising. Nevertheless, there are precursors known for the FEBID process, for which the chemical composition is almost independent of the deposition parameters dwell-time and pitch. A prominent example is $\mathrm{MeCpPt}(\mathrm{Me})_{3}$. However, in this case it could be shown that the resulting $\mathrm{Pt}-\mathrm{C}$ deposits are very sensitive to post-treatment either by annealing [30-32] or electron-beam irradiation $[3,8,9,33]$, which can result in an increase of conductivity of many orders of magnitude. In order to investigate the influence of the GA for such a post-treatment process of FEBID deposits several $\mathrm{Pt}-\mathrm{C}$ test-structures were fabricated via FEBID by using identical depostion parameters $\left(U=5 \mathrm{kV}, I=1.6 \mathrm{nA}, t_{\mathrm{D}}=1 \mu \mathrm{s}, p_{\mathrm{x}}=40 \mathrm{~nm}, p_{\mathrm{y}}=40 \mathrm{~nm}\right)$ and an electron dose of $30 \mathrm{nC} / \mu \mathrm{m}^{2}$. This results in a height of the deposits of approximately $120 \mathrm{~nm}$, which ensures a complete penetration of the deposit by the electrons. As proposed by Plank et al. [33] RRL-like conditions as the best initial conditions for e-beam curing were used for the deposition of $\mathrm{Pt}-\mathrm{C}$ deposits, as non-dissociated precursor molecules are incorporated in the deposit. Afterwards each of the identical deposits was irradiated with the electron-beam of the SEM while using: (1) standard parameters serving as a reference sample $\left(t_{\mathrm{D}}=1 \mu \mathrm{s}, p_{\mathrm{x}}=p_{\mathrm{y}}=40 \mathrm{~nm}\right),(2)$ GA for dwell-time optimization $\left(t_{\mathrm{D}}=0.2-1500 \mu \mathrm{s}, p_{\mathrm{x}}=p_{\mathrm{y}}=40 \mathrm{~nm}\right)$, and (3) GA for pitch optimization $t_{\mathrm{D}}=1 \mu \mathrm{s}, p_{\mathrm{x}}, p_{\mathrm{y}}=10-100 \mathrm{~nm}$ (Figure 5). As can be seen in Figure 5, in contrast to the previous experiments for the deposition of $\mathrm{W}(\mathrm{CO})_{6}$, the variation of the irradiation parameters for dwell-time and pitch does not influence the rate of change of conductance over time, which is in all cases very high. Therefore, for electron post-treatment of samples that were deposited with the Pt-based precursor $\mathrm{MeCpPt}(\mathrm{Me})_{3}$ no parameter sets that might result in a significantly faster enhancement of the conductance could be identified with the GA.

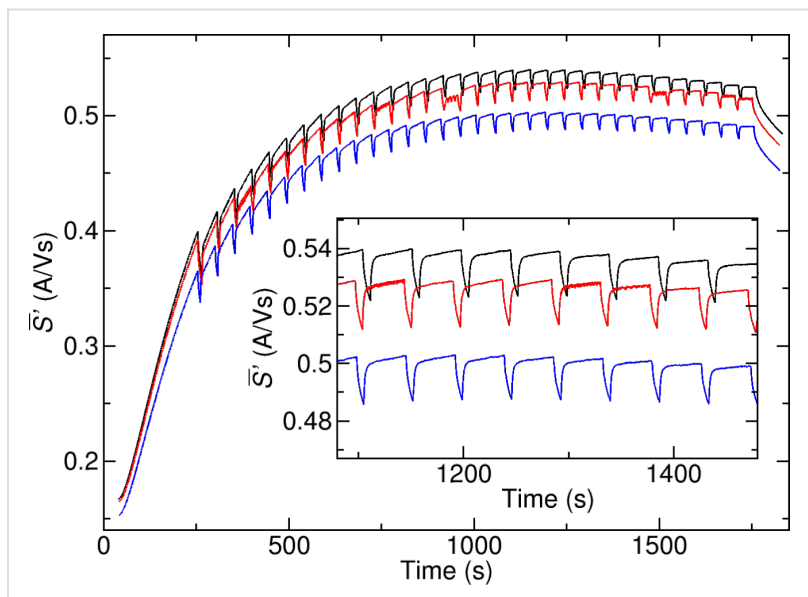

Figure 5: Time-dependent rate of change of conductance for $\mathrm{Pt}-\mathrm{C}$ deposits - The GA is applied for the optimization of conductance during post-irradiation with electrons $\left(U=5 \mathrm{kV}, I_{\text {nominal }}=6.3 \mathrm{nA}\right)$. Reference sample (blue): $t_{\mathrm{D}}=1 \mu \mathrm{s}, p_{\mathrm{x}}=p_{\mathrm{y}}=40 \mathrm{~nm}$, sample for GA dwell-time optimization (red): $t_{\mathrm{D}}=0.2-1500 \mu \mathrm{s}, p_{\mathrm{x}}=p_{\mathrm{y}}=40 \mathrm{~nm}$, sample for GA pitch optimization (black): $t_{\mathrm{D}}=1 \mu \mathrm{s}, p_{\mathrm{x}}, p_{\mathrm{y}}=10-100 \mathrm{~nm}$. A variation of the beam-parameters dwell-time and pitch during post-growth electron treatment does not influence the rate of change of conductance during e-beam irradiation for $\mathrm{Pt}-\mathrm{C}$ deposits compared to the reference (inset) The offsets in the conductance data result from small variations of conductance of the seed layer.

According to Plank et al. the post-growth irradiation-induced dissociation of the incorporated molecules leads either to the creation of small Pt-crystallites between existing Pt-crystals in the nanogranular structure of $\mathrm{Pt}-\mathrm{C}$ or to a growth of the previously present Pt-crystallites that leads to a reduction of the intergrain distance and therefore to a decreasing resistivity [33]. We found that, as already shown in previous experiments [9], the resistivity could be reduced during e-beam curing, however, independent of dwell-time and pitch. This can be expected because precursor depletion as the dominant factor during deposition does not play a role during e-beam curing. Furthermore, effects like the growth of existing Pt crystals should depend on the electron dose rather than on parameters such as dwell-time or pitch for post-irradiation of samples at fixed dose.

\section{Conclusion}

In this work we presented the application of an evolutionary GA for the in situ optimization of FEBID nanostructures with regard to their electrical conductivity. By using the gradient of the measured in situ rate of change of conductance as a fitness parameter the GA was able to tune the metal content of tungsten deposits created from $\mathrm{W}(\mathrm{CO})_{6}$ over a large range by either targeting the highest or lowest conductance, respectively. This 
resulted in a difference in conductivity of one order of magnitude. This experiment highlights the effectiveness of the procedure for precursors for which the chemical composition of the deposit is sensitive to the deposition parameters. In a second experiment the GA was applied for the post-treatment of $\mathrm{Pt}-\mathrm{C}$ deposits that were obtained from the precursor $\mathrm{MeCpPt}(\mathrm{Me})_{3}$ by electron-beam irradiation. For this system the GA revealed that solely the applied electron dose and not specific irradiation parameters leads to the observed strong increase of conductance over time.

The presented technique can be applied to all beam-induced deposition processes and has great potential for the further optimization or tuning of parameters for nanostructures prepared by FEBID or related techniques. In particular the finding of optimized deposition parameters for new precursor materials, which in general is a very time-consuming and often an arbitrary process, can be achieved in a fast and efficient way. The fact that the GA is independent of the mechanism that is responsible for the enhancement of conductance (e.g., increase of metal content, changes of height of the deposit, structural or phase changes, etc.) and its adaption to every experimental circumstance with direct feedback promises a significant potential for future FEBID research. Furthermore, the application of the GA is not restricted to the optimization of conductance but can also be applied to, e.g., optimize dielectric properties of FEBID deposits by using capacative measurements or optical reflectivity. Especially it will play a major role for the analysis and optimization of FEBID binary systems that have been recently adressed [11-13]. Some of us were able to stabilize an amorphous, metastable $\mathrm{Pt}_{2} \mathrm{Si}_{3}$ phase, which showed a maximum of conductivity compared to other Pt-Si samples with different stoichiometric proportions of platinum and silicon [11]. In follow-up experiments it will be shown, that the GA can be applied to obtain deposition parameters for binary systems, e.g., $\mathrm{Pt}-\mathrm{Si}$ or $\mathrm{Co}-\mathrm{Pt}$, which automatically leads to the formation of the binary phases with the highest conductivity.

\section{Acknowledgements}

The authors acknowledge financial support by the BeilsteinInstitut, Frankfurt/Main, Germany within the research collaboration NanoBiC.

\section{References}

1. Boero, G.; Utke, I.; Bret, T.; Quack, N.; Todorova, M.; Mouaziz, S.; Kejik, P.; Brugger, J.; Popovic, R. S.; Hoffmann, P. Appl. Phys. Lett. 2005, 86, 042503. doi:10.1063/1.1856134

2. Serrano-Ramón, L.; Córdoba, R.; Rodríguez, L. A.; Magén, C.; Snoeck, E.; Gatel, C.; Serrano, I.; Ibarra, M. R.; De Teresa, J. M. ACS Nano 2011, 5, 7781-7787. doi:10.1021/nn201517r
3. Schwalb, C. H.; Grimm, C.; Baranowski, M.; Sachser, R.; Porrati, F.; Reith, H.; Das, P.; Müller, J.; Völklein, F.; Kaya, A.; Huth, M. Sensors 2010, 10, 9847-9856. doi:10.3390/s101109847

4. Huth, M.; Porrati, F.; Schwalb, C.; Winhold, M.; Sachser, R.; Dukic, M.; Adams, J.; Fantner, G. Beilstein J. Nanotechnol. 2012, 3, 597-619. doi:10.3762/bjnano.3.70

5. Kolb, F.; Schmoltner, K.; Huth, M.; Hohenau, A.; Krenn, J.; Klug, A.; List, E. J. W.; Plank, H. Nanotechnology 2013, 24, 305501. doi:10.1088/0957-4484/24/30/305501

6. Fernández-Pacheco, A.; De Teresa, J. M.; Córdoba, R.; Ibarra, M. R.; Petit, D.; Read, D. E.; O’Brien, L.; Lewis, E. R.; Zeng, H. T.; Cowburn, R. P. Appl. Phys. Lett. 2009, 94, 192509. doi:10.1063/1.3139068

7. Serrano-Ramón, L.; Fernández-Pacheco, A.; Ibarra, M. R.; Petit, D.; Cowburn, R. P.; Tyliszczak, T.; De Teresa, J. M. Eur. Phys. J. B 2013, 86, 97. doi:10.1140/epjb/e2013-30926-5

8. Sachser, R.; Porrati, F.; Schwalb, C. H.; Huth, M. Phys. Rev. Lett. 2011, 107, 206803. doi:10.1103/PhysRevLett.107.206803

9. Porrati, F.; Sachser, R.; Schwalb, C. H.; Frangakis, A. S.; Huth, M. J. Appl. Phys. 2011, 109, 063715. doi:10.1063/1.3559773

10. Porrati, F.; Sachser, R.; Huth, M. Nanotechnology 2009, 20, 195301. doi:10.1088/0957-4484/20/19/195301

11. Winhold, M.; Schwalb, C. H.; Porrati, F.; Sachser, R.; Frangakis, A. S.; Kämpken, B.; Terfort, A.; Auner, N.; Huth, M. ACS Nano 2011, 5, 9675-9681. doi:10.1021/nn203134a

12. Porrati, F.; Begun, E.; Winhold, M.; Schwalb, C. H.; Sachser, R.; Frangakis, A. S.; Huth, M. Nanotechnology 2012, 23, 185702. doi:10.1088/0957-4484/23/18/185702

13. Che, R. C.; Takeguchi, M.; Shimojo, M.; Zhang, W.; Furuya, K. Appl. Phys. Lett. 2005, 87, 223109. doi:10.1063/1.2136071

14. Rosenberg, S. G.; Landheer, K.; Hagen, C. W.; Fairbrother, D. H. J. Vac. Sci. Technol. B 2012, 30, 051805-051814. doi:10.1116/1.4751281

15. Rosenberg, S. G.; Barclay, M.; Fairbrother, D. H. Phys. Chem. Chem. Phys. 2013, 15, 4002-4015. doi:10.1039/C3CP43902J

16. Mulders, J. J. L.; Belova, L. M.; Riazanova, A. Nanotechnology 2011, 22, 055302. doi:10.1088/0957-4484/22/5/055302

17. Patent pending DE 102013004 116.3.

18. Landheer, K.; Rosenberg, S. G.; Bernau, L.; Swiderek, P.; Utke, I.; Hagen, C. W.; Fairbrother, D. H. J. Phys. Chem. C 2011, 115, 17452-17463. doi:10.1021/jp204189k

19. Hoyle, P. C.; Ogasawara, M.; Cleaver, J. R. A.; Ahmed, H. Appl. Phys. Lett. 1993, 62, 3043-3045. doi:10.1063/1.109133

20. Bauerdick, S.; Linden, A.; Stampfer, C.; Helbling, T.; Hierold, C. J. Vac. Sci. Technol., B 2006, 24, 3144-3147. doi:10.1116/1.2388965

21. Huth, M.; Klingenberger, D.; Grimm, C.; Porrati, F.; Sachser, R. New J. Phys. 2009, 11, 033032. doi:10.1088/1367-2630/11/3/033032

22. Utke, I.; Michler, J.; Gasser, P.; Santschi, C.; Laub, D.; Cantoni, M.; Buffat, P. A.; Jiao, C.; Hoffmann, P. Adv. Eng. Mater. 2005, 7, 323-331. doi:10.1002/adem.200500061

23. Lukasczyk, T.; Schirmer, M.; Steinrück, H.-P.; Marbach, H. Small 2008, 4, 841-846. doi:10.1002/smll.200701095

24. Shimojo, M.; Takeguchi, M.; Furuya, K. Nanotechnology 2006, 17, 3637-3640. doi:10.1088/0957-4484/17/15/003

25. van Dorp, W. F.; Hagen, C. W. J. Appl. Phys. 2008, 104, 081301. doi:10.1063/1.2977587

26. van Dorp, W. F.; Wnuk, J. D.; Gorham, J. M.; Fairbrother, D. H.; Madey, T. E.; Hagen, C. W. J. Appl. Phys. 2009, 106, 074903. doi:10.1063/1.3225091 
27. Fowlkes, J. D.; Rack, P. D. ACS Nano 2010, 4, 1619-1629. doi:10.1021/nn901363a

28. Moore, G. E. J. Appl. Phys. 1961, 32, 1241-1251. doi:10.1063/1.1736212

29. Lambert, R. M.; Comrie, C. M. Surf. Sci. 1973, 38, 197-209. doi:10.1016/0039-6028(73)90283-5

30. Tsukatani, Y.; Yamasaki, N.; Murakami, K.; Wakaya, F.; Takai, M. Jpn. J. Appl. Phys. 2005, 44, 5683-5686. doi:10.1143/JJAP.44.5683

31. Langford, R. M.; Wang, T.-X.; Ozkaya, D. Microelectron. Eng. 2007, 84, 784-788. doi:10.1016/j.mee.2007.01.055

32. Botman, A.; Mulders, J. J. L.; Hagen, C. W. Nanotechnology 2009, 20, 372001. doi:10.1088/0957-4484/20/37/372001

33. Plank, H.; Kothleitner, G.; Hofer, F.; Michelitsch, S. G.; Gspan, C.; Hohenau, A.; Krenn, J. J. Vac. Sci. Technol., B 2011, 29, 051801. doi:10.1116/1.3622314

\section{License and Terms}

This is an Open Access article under the terms of the Creative Commons Attribution License

(http://creativecommons.org/licenses/by/2.0), which permits unrestricted use, distribution, and reproduction in any medium, provided the original work is properly cited.

The license is subject to the Beilstein Journal of

Nanotechnology terms and conditions:

(http://www.beilstein-journals.org/bjnano)

The definitive version of this article is the electronic one which can be found at: $\underline{\text { doi:10.3762/bjnano.4.103 }}$ 